Research Article

\title{
Numerical Analysis Method of Shear Properties of Infilled Joints under Constant Normal Stiffness Condition
}

\author{
Xiangyu Wang $\mathbb{D},{ }^{1}$ Ruofan Wang $\mathbb{D}{ }^{1}$ and Zizheng Zhang $\mathbb{D}^{2,3}$ \\ ${ }^{1}$ School of Mines, Key Laboratory of Deep Coal Resource Mining, Ministry of Education of China, \\ China University of Mining and Technology, Xuzhou 221116, China \\ ${ }^{2}$ State Key Laboratory of Mining Disaster Prevention and Control Co-founded by Shandong Province and the \\ Ministry of Science and Technology, Shandong University of Science and Technology, Qingdao 266590, China \\ ${ }^{3}$ Work Safety Key Lab on Prevention and Control of Gas and Roof Disasters for Southern Goal Mines, \\ Hunan University of Science and Technology, Xiangtan 411201, China
}

Correspondence should be addressed to Zizheng Zhang; 1010096@hnust.edu.cn

Received 13 January 2018; Accepted 5 June 2018; Published 1 August 2018

Academic Editor: Gaofeng Zhao

Copyright ( 2018 Xiangyu Wang et al. This is an open access article distributed under the Creative Commons Attribution License, which permits unrestricted use, distribution, and reproduction in any medium, provided the original work is properly cited.

The direct shear test is implemented in this paper for infilled joints under constant normal stiffness (CNS) condition with the finite difference software FLAC3D. The CNS condition was performed based on a servoprogram developed by FISH language. The effects of initial normal stress, undulating angle, and infilled ratio on the shear failure mode of infilled joints under CNS are revealed based on numerical simulation. It is found that the shear strength of infilled joints will grow along with the increase of the undulating angle and the decrease of the infilled ratio. The numerical analysis method is also able to quantify the effect of multiple factors (initial normal stress and infilled ratio) on shear properties of infilled joints. The model shows a good agreement with the experimental results available in the literatures. Therefore, this study proposed and verified a numerical analysis method capable of studying the effects of normal stress, undulating angles, and infilled ratio on the shear behavior of infilled rock joints.

\section{Introduction}

With the combined action of tectonics, groundwater movement, and weathering, some joints are filled with soft geologic materials, such as clay and sand. These soft fillings significantly weaken the shear strength of jointed rock and make the rock present more obvious heterogeneity and anisotropy. Infilled joints generally become the weakest position under shear which will easily trigger the whole instability of engineering rock [1-4]. Therefore, the study of shear properties of infilled joints is of significance in both stability evaluation and reinforcement of engineering rock. Many direct shear tests have been conducted to study the influence of different factors on the shear failure mode of infilled joints. These influenced factors mainly included material type, surface morphology, initial normal stress, infilled ratio, fillings saturation degree, and overconsolidation degree [1,5-7]. Previous test results showed that soft fillings, such as Green mudstone, serpentinite, and clay, will significantly reduce the shear strength of infilled joints [8], while the high-strength fillings, such as mortar and concrete, enhance the shear strength [6]. It was found that different morphology of infilled joints may bring about different shear failure mechanism. Furthermore, the large joint undulating degree will prevent the roll of filling grain. It is easy to understand that the shear failure of infilled joints should overcome the sliding friction of fillings. However, when the joint surface is flat providing little resistance to the movement of filling grain, the shear failure only needs to overcome the rolling friction $[9,10]$. Laboratory results from both Ladanyi and Archambault's [11] and Indraratna's [12] direct shear tests showed that the increase of joint undulation was able to enhance the shear strength of infilled joints. On the contrary, normal stress controls the shear failure mode of infilled joints in a certain degree. With the small normal stress, the sliding of infilled joints only occurs in soft fillings and along the surface of protruding block in the sliding face. However, the large normal stress-induced 


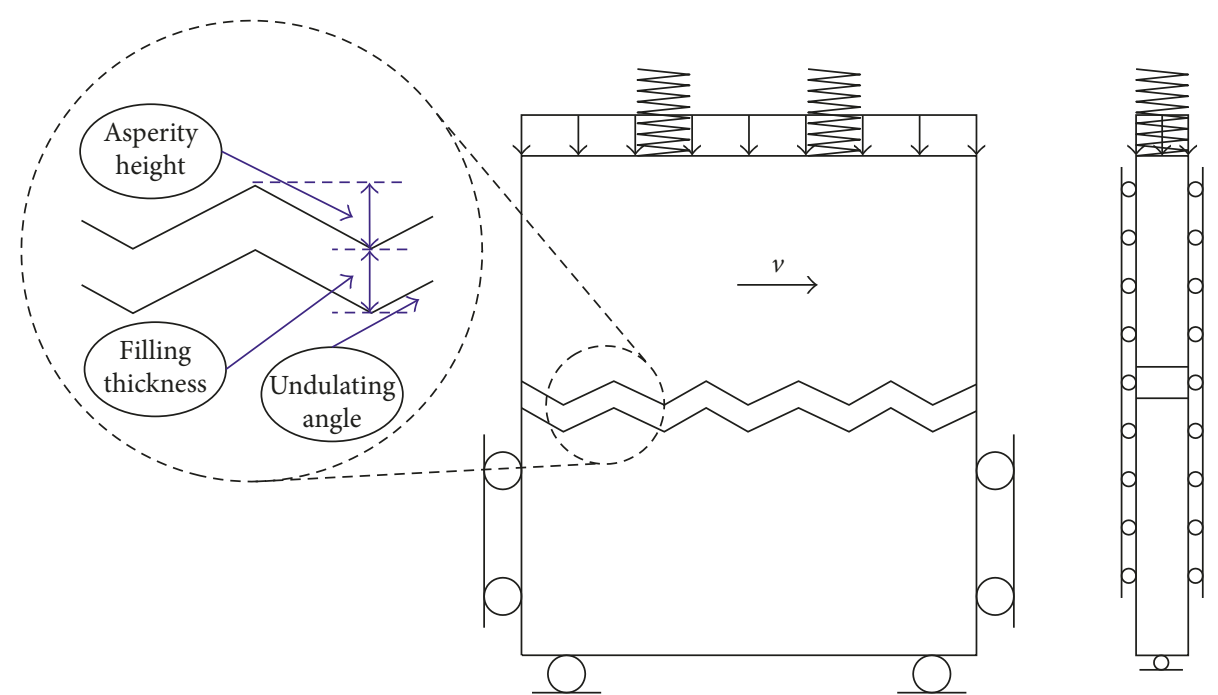

(a)

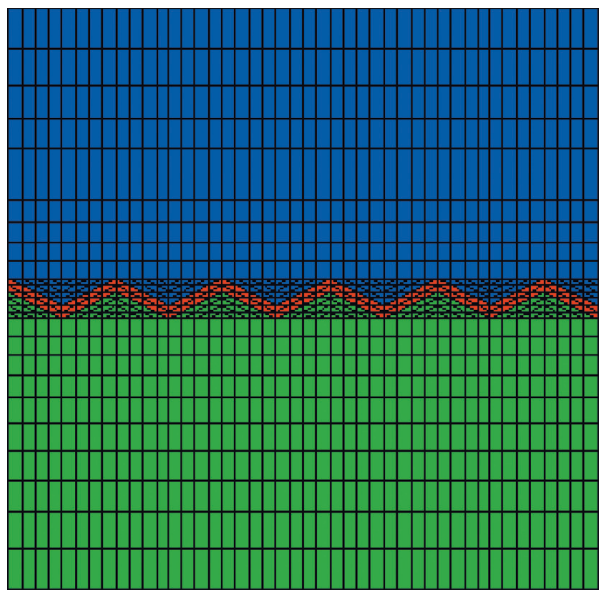

(b)

FIgURE 1: (a) Concept model and (b) numerical model of the infilled joint.

sliding will cut the protruding block which means the yield of both soft fillings and rock [11]. Meanwhile, the infilled ratio, that is, the ratio of filling thickness, $t$, and the asperity height, $a$, is a significant factor controlling the shear properties of infilled joints. A large number of direct shear test results $[1,3,12-16]$ showed that the infilled ratio, $t / a$, has a critical value. If the infilled ratio is less than the critical value, the shear failure strength of infilled joints is typically higher than the shear strength of fillings but lower than that of asperity. If the infilled ratio is greater than the critical value, the shear behaviors are totally controlled by fillings that means the shear strength of the infilled joints will be equal to that of the fillings. Xu and Ren [17] also obtained similar conclusions from the numerical direct shear test. Indraratna [12] pointed out that the critical value of the infilled ratio under CNS condition was less than that under constant normal load/stress (CNL) condition while small initial normal stress corresponded to a small critical value of the infilled ratio.

Most of previous direct shear tests were conducted under CNL condition [12, 18-21]. However, for underground rock mass, the normal stress applied on rock joints will increase due to both dilatancy effect and restraining effect of surrounding rock. Thus, the laboratory results under CNL condition cannot accurately reflect the shear failure mode of joints in underground rock mass. Furthermore, current research achievements are mainly based on laboratory direct shear tests. As there are many factors influencing the shear properties of infilled joints as mentioned above, studying the effect of all these factors require a large number of direct shear tests which is inconvenient. Therefore, numerical simulation, as a repeatable and highly efficient research method, is of great advantages. The paper will provide a numerical simulation method to implement the direct shear test under CNS condition. The capability of the numerical simulation method for evaluating effects of different factors including undulating angles, infilled ratio, and normal stress levels on shear properties of infilled joints will be studied and discussed.

\section{Numerical Model of Direct Shear Test}

2.1. Modeling of Infilled Joint. This paper developed a concept model for infilled joints (shown in Figure 1(a)) in which 


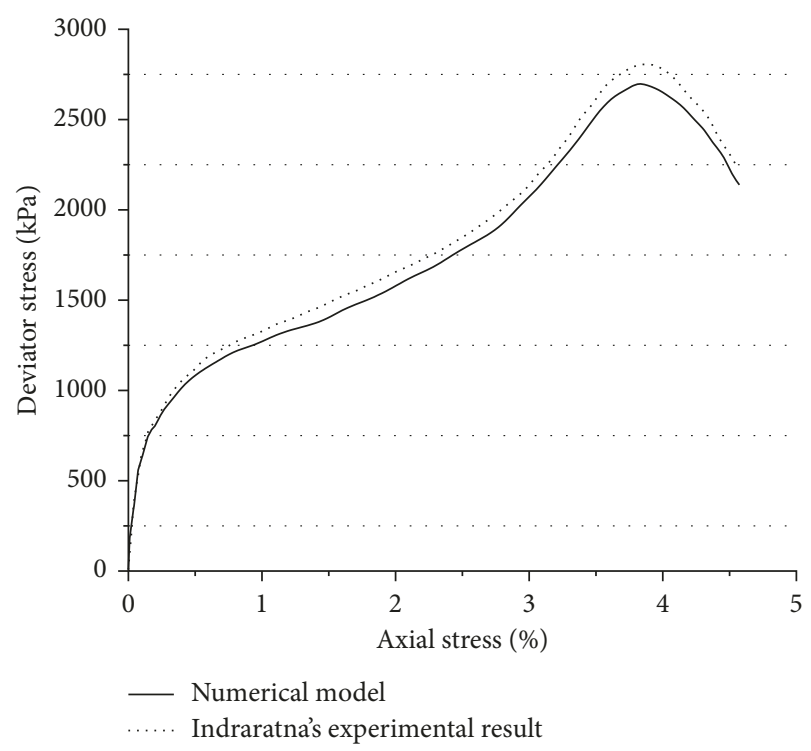

Figure 2: Comparison of the stress-strain curve obtained by the numerical model to that of Indraratna's experiment.

the joint surface is idealized as sawtooth shape. The model consists of two rock blocks lying top and bottom sides, respectively, with soft fillings in the middle. An interface is added between the top rock and the filling to simulate the shear slip phenomenon. This study used a wedge-shaped element to build a sawtooth-shaped joint in the middle part of the model while the block element was applied to build the top and bottom parts of the model for improving the calculation efficiency. In the numerical model developed by FLAC3D, as shown in Figure 1(b), the length $\times$ width $\times$ height (without fillings) of the model is $2.0 \mathrm{~m} \times 0.2 \mathrm{~m} \times 2.1 \mathrm{~m}$. The height and bottom length of a sawtooth are $0.1 \mathrm{~m}$ and $0.4 \mathrm{~m}$, respectively.

2.2. Mechanical Parameters. The Mohr-Coulomb failure criterion is adopted as the constitutive model for both rock and filling. The bulk modulus and shear modulus used in FLAC3D can be calculated from the elastic modulus and Poisson's ratio based on the generalized Hook's Law.

The normal stiffness and shear stiffness of interface refer to the recommendation value in the FLAC3D manual [22], namely, ten times the equivalent stiffness of the stiffest neighboring zone, as shown in the following equation:

$$
k_{\mathrm{n}}=k_{\mathrm{s}}=10 \times \max \left[\frac{K+4 G / 3}{\Delta z_{\min }}\right] \text {, }
$$

where $k_{\mathrm{n}}$ is the normal stiffness, $k_{\mathrm{s}}$ is the shear stiffness, $K$ is the bulk modulus, $G$ is the shear modulus, and $\Delta z_{\min }$ is the smallest width of an adjoining zone in the normal direction.

2.3. Boundary Conditions. The bottom boundary and right boundary are fixed in the $z$-axis and $x$-axis directions, respectively. Both the front boundary and back boundary are fixed in the $y$-axis direction. A certain normal stress and CNS condition are applied on the top boundary of the model.
Then a very small shearing rate $\left(4 \times 10^{-7} \mathrm{~m} / \mathrm{step}\right)$ is applied on all the nodes in the top block. In this model, CNS condition is implemented through a servoprogram developed by the FISH code. The executing processes of the servoprogram are illustrated as follows. The whole shearing process is divided into many shearing cycles. In each cycle, the test runs 100 steps under the constant normal stress, $\sigma_{\mathrm{n}}$. Then, the normal displacement of the top block, $\Delta \delta_{n}$, generated in this cycle is monitored. If the constant normal stiffness, $k_{\mathrm{n}}$, is set to be $4.0 \mathrm{MPa} / \mathrm{m}$, the increment of normal stress, $\Delta \sigma_{\mathrm{n}}$, should be $\Delta \delta_{\mathrm{n}} \times k_{\mathrm{n}}$ in this cycle. The normal stress applied on the top boundary in the next shearing cycle will be adjusted to be $\sigma_{\mathrm{n}}^{\prime}=\sigma_{\mathrm{n}}+\Delta \sigma_{\mathrm{n}}$. The above shearing cycle should be executed 5500 times so that the shearing displacement can reach $0.22 \mathrm{~m}$ (larger than the half of bottom length of sawtooth). In addition, the CNL condition can be achieved by setting the constant normal stiffness as 0 .

In order to validate the reliability of this numerical model, we rotate this model to imitate Indraratna's shear strength experiment of infilled rock joints [14] and compare it with the experimental results (Figure 2). Obviously, comparison shows a good agreement between the numerical model and experimental results. Therefore, this model is considered capable of being further used to analyze the shear mechanical properties of infilled joints under CNS condition.

2.4. Variables Monitoring. The main purpose of the direct shear test is to obtain the changing tendency of three variables (shear stress, normal stress, and normal displacement) along with shearing displacement. In shearing process, the three variables were calculated by the FISH code and extracted by the HISTORY command. The shear stress is the ratio of the maximum $x$-axis unbalance force of the bottom block to the shearing area of the infilled joint.

\section{Numerical Results and Discussion}

In this section, the numerical model of the direct shear test is used to study the influence of different factors, including different loading conditions (CNS and CNL), joint undulation, and infilled ratio, on shear properties of rock joints. Then, the numerical results combined with the previous studies $[12,15-17,23]$ are discussed. The mechanical parameters of rock and fillings are listed in Table 1.

\subsection{Shear Properties under CNS and CNL Conditions. In this} test, the infilled ratio, $t / a$, is 0 . The undulating angle is $26.6^{\circ}$. The initial normal stresses were set to be $0.1 \mathrm{MPa}, 0.3 \mathrm{MPa}$, 0.5 MPa, 0.7 MPa, 0.9 MPa, 1.1 MPa, and 1.3 MPa. Direct shear tests are conducted under CNS and CNL conditions, respectively, as shown in Figure 3. The shear stress-shear displacement curve, normal displacement-shear displacement curve, and normal stress-shear displacement curve obtained from numerical simulation are shown in Figure 4.

Figure 4(a) illustrates the shear stress evolution of a clean (without fillings) joint under CNS and CNL conditions. It is found that if the direct shear test is conducted under CNS 
TABLE 1: Mechanical parameters of infilled joints.

\begin{tabular}{lccccc}
\hline & Elastic modulus $(\mathrm{GPa})$ & Poisson's ratio & Friction angle $\left(^{\circ}\right)$ & Cohesion $(\mathrm{MPa})$ & Tensile strength $(\mathrm{MPa})$ \\
\hline Rock & 2.6 & 0.3 & 36.0 & 1.3 & 5.17 \\
Filling & 0.25 & 0.35 & 25.0 & 0.4 & 1.29 \\
\hline
\end{tabular}

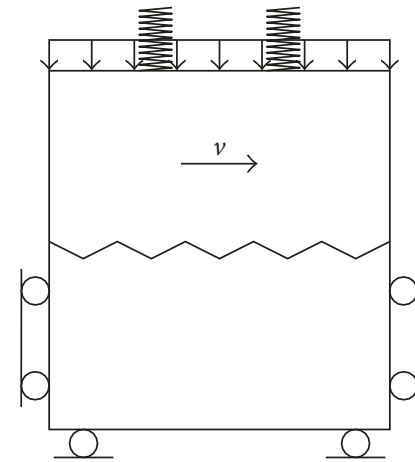

(a)

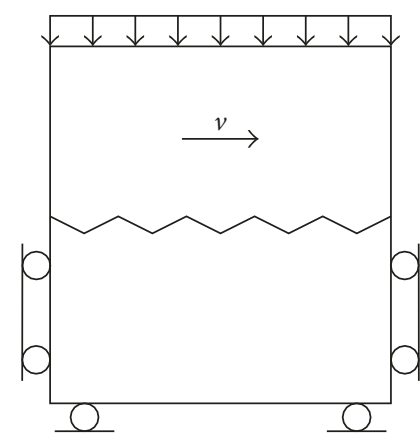

(b)

FIgure 3: Direct shear tests under (a) CNS and (b) CNL conditions.

condition or CNL condition, there are two inflection points in the stress-displacement curve. The whole curve can be divided into three parts by these two points which represent elastic part, yield part, and failure part, respectively. In the elastic part, shear stress increases linearly and grows to the first inflection point at a very small shear displacement. It should be noted that the first inflection point under different loading conditions (CNS and CNL) shows the same shear stress value. In the yield part lying between the two inflection points, the shear stress stays stable under CNL condition. However, it continues increasing linearly with displacement under CNS condition. With a certain shear displacement, the shear stress reaches the second inflection point whose value is regarded as the shear strength of joints. Then, the curve comes into the failure part in which the shear stress reduces gradually under both types of conditions. It can be seen that, at any level of initial normal stress, the shear strength under CNS condition is greater than that under CNL. However, the corresponding shear displacement under CNS condition is smaller. In addition, the shear strength of joint shows an upward trend with the increase of initial normal stress, while the corresponding shear displacement reduces gradually under both loading conditions.

Figure 4(b) displays the dilation curves of joint under CNS and CNL conditions. It can be seen that the dilation curve shows a linearly increasing trend at the initial shearing stress stage. It is worth mentioning that the dilatancy angle is equal to the angle of sawtooth on the bottom. This means that there is no deformation failure occurring in the sawtooth, and the top block is sliding along the contour line of sawtooth from the root to the top of sawtooth. With the shear proceeding, the contact area between two sawteeth reduces gradually, causing a decrease in shear strength of sawtooth. Once the strength drops to a certain value, the top block will cut off the sawtooth rather than sliding along the contour line which makes the dilation curve appear an inflection point. Then the normal displacement rate gradually decreases, approaching to a certain value eventually. At the same initial normal stress, the cutoff position on the sawtooth is more close to the tooth root for CNS condition which means the dilatancy effect is restrained due to the increase of normal stress.

Figure 4(c) shows the normal stress evolution under two types of conditions. It can be seen that the normal stress under CNL always keeps stable during the shear process. In contrast, the normal stress under CNS experiences a linear increasing trend at the beginning and then decelerates slowly to approach a certain value.

In conclusion, the dilatancy effect of the joint will be restrained under CNS condition due to the increase of normal stress, causing the squeezing action between two sawteeth to grow gradually. Therefore, the sheared position of sawtooth is more close to the tooth root under CNS condition which is good for the sawtooth to exert its antishear ability. Indraratna [12] obtained the similar conclusions through conducting laboratory direct shear tests under CNS and CNL conditions. The difference is that shear stress curves obtained by Indraratna present obvious strain softening characteristics which were not observed in the numerical results. This is because that the Mohr-Coulomb criterion applied in the numerical model is not able to reflect the postpeak mechanical characteristics.

In addition, previous studies [24-26] showed that infilled joints demonstrate three different failure modes based on discrete element numerical simulation which are failure of the interface between rock and fillings, sliding along the interface, and the cutoff failure of the sawtooth as shown in Figure 5. It can be found that the shear failure mode of infilled joints is influenced by mechanical properties of rock, fillings, and interface. Meanwhile, based on the investigation of the failure mode under different conditions (e.g., normal stress, undulating angle, and infilled ratio), this 

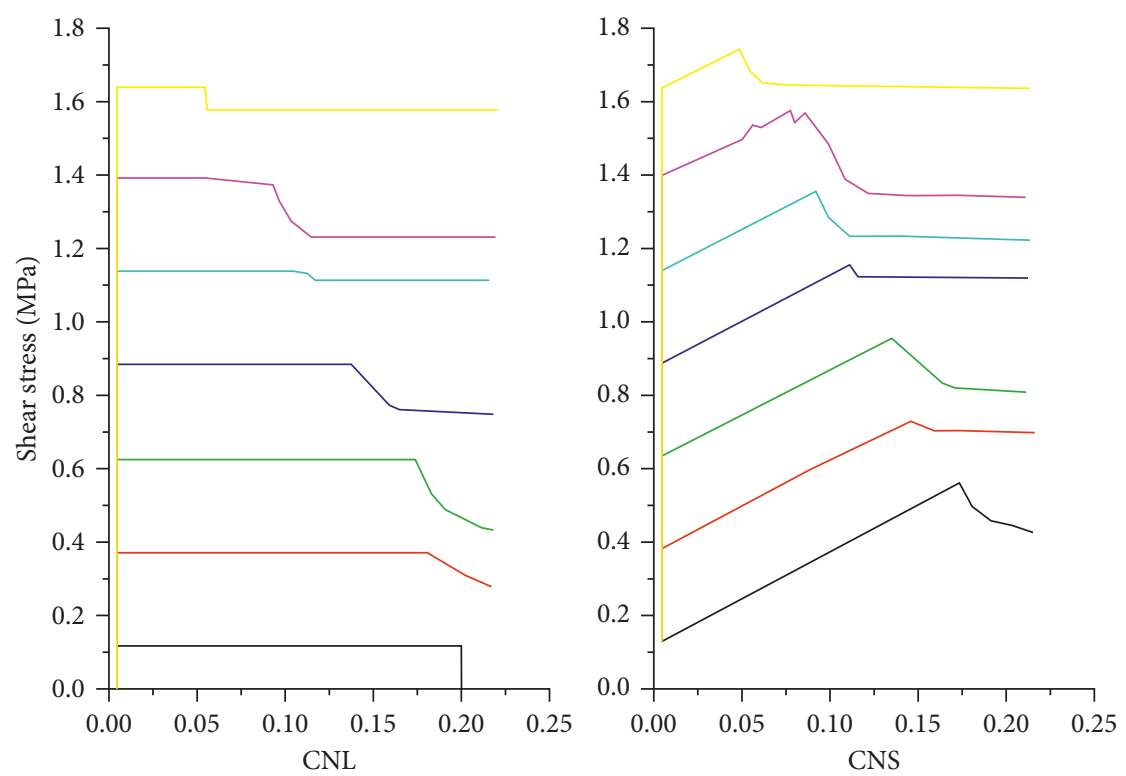

Shear displacement (m)

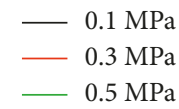

$-0.7 \mathrm{MPa}$
$-0.9 \mathrm{MPa}$

$1.1 \mathrm{MPa}$

(a)
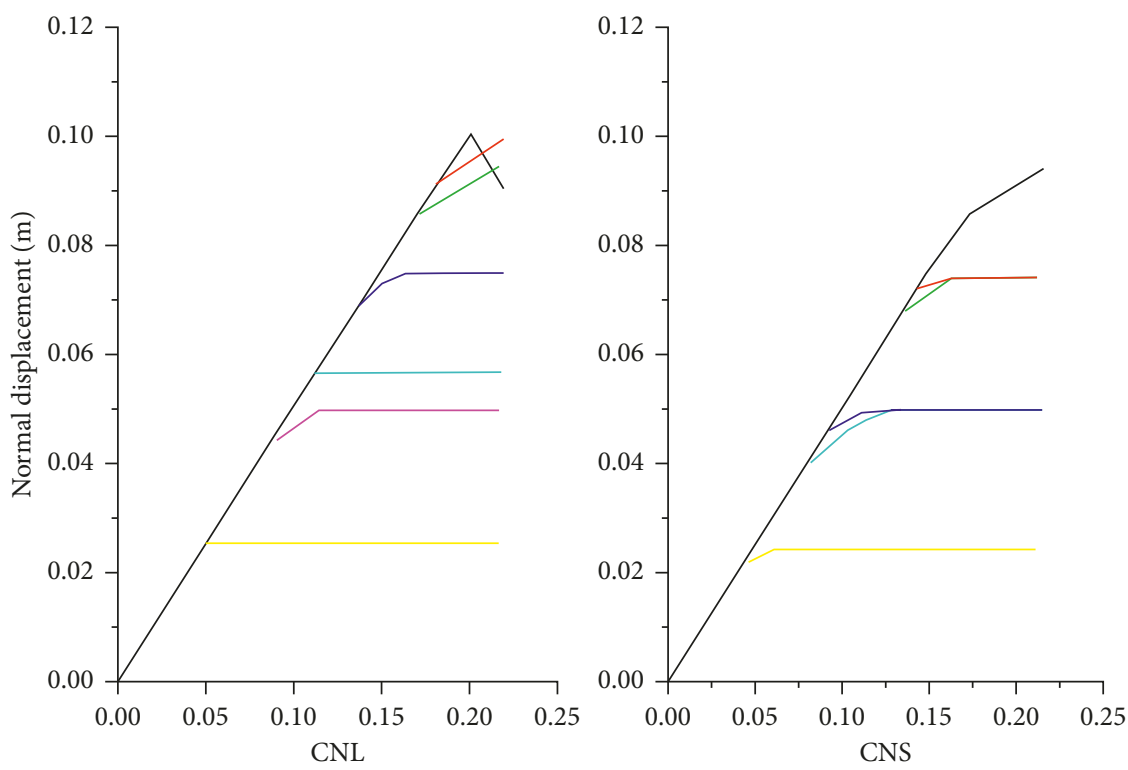

Shear displacement $(\mathrm{m})$

$0.1 \mathrm{MPa}$
$-\quad 0.3 \mathrm{MPa}$
$-\quad 0.5 \mathrm{MPa}$

$\begin{array}{ll}- & 0.7 \mathrm{MPa} \\ - & 0.9 \mathrm{MPa}\end{array}$

- $1.1 \mathrm{MPa}$

- $1.3 \mathrm{MPa}$

(b)

FIgUre 4: Continued. 

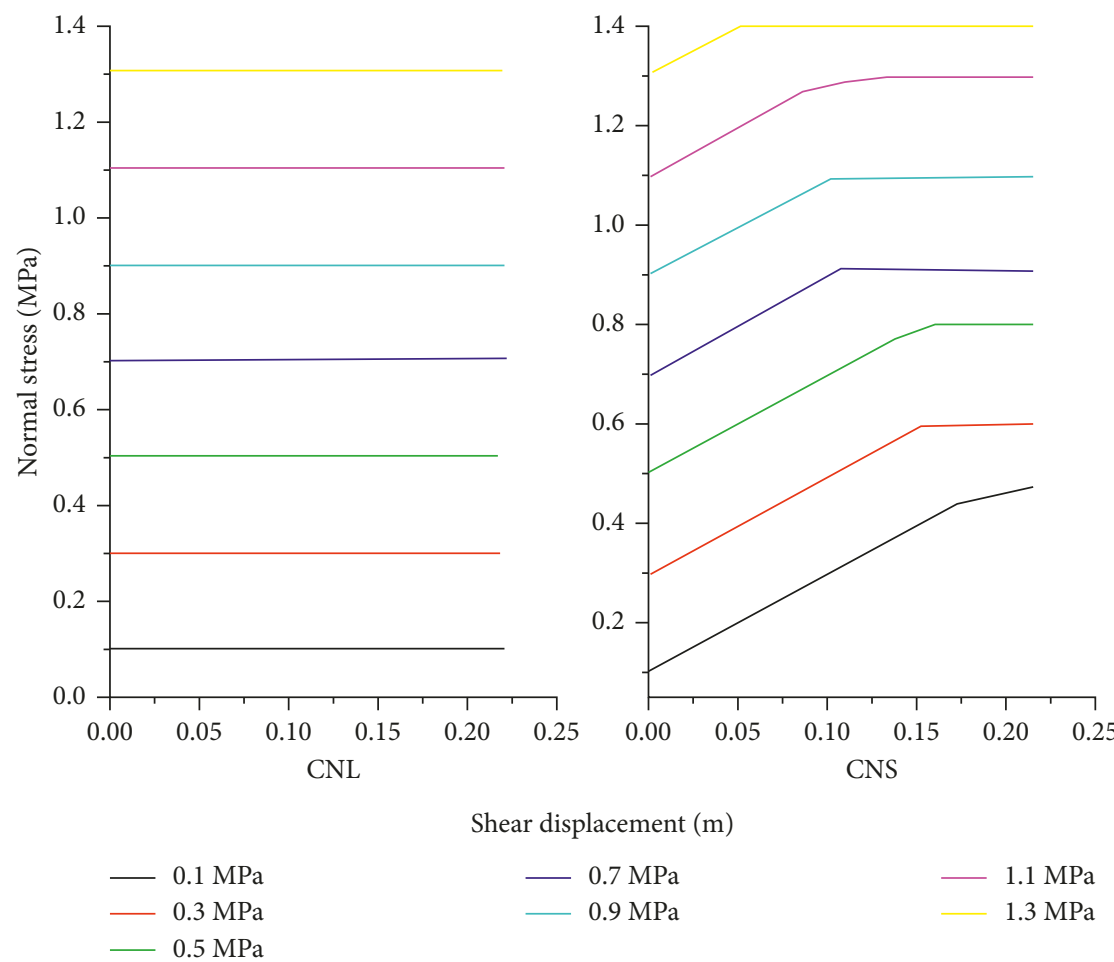

Shear displacement $(\mathrm{m})$

\begin{tabular}{l}
$-0.7 \mathrm{MPa}$ \\
$-0.9 \mathrm{MPa}$ \\
$-1.1 \mathrm{MPa}$ \\
\hline
\end{tabular}

(c)

FIGURE 4: Shearing characteristics curve of the clean joint under CNL and CNS conditions. (a) Shear stress-shear displacement curve. (b) Normal displacement-shear displacement curve. (c) Normal stress-shear displacement curve.

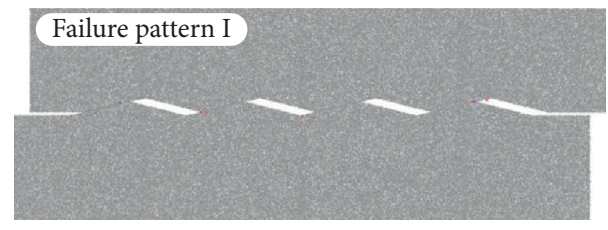

(a)

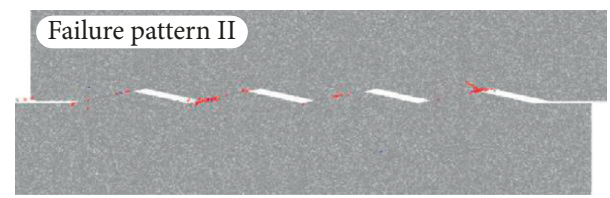

(b)

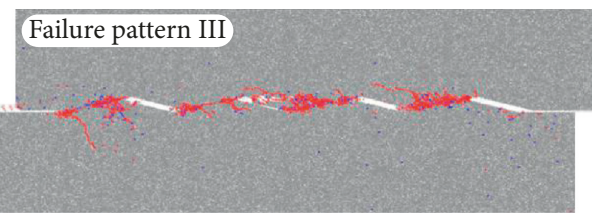

(c)

Figure 5: Shear modes of infilled joints. (a) Failure of the interface between rock and fillings, (b) sliding along the interface, and (c) the cutoff failure of the sawtooth. Red points: tensile crack and blue points: shear crack (adopted from Bahaaddini et al., [25]).

study reveals that shear failure of infilled joints can be divided into three phases which are elastic phase, yield phase, and failure phase while each phase corresponds to a specific failure mode as shown in the literatures. Therefore, the numerical model in this study shows a good agreement with previous studies [24-26].

\subsection{Influence of Undulating Angle on Shear Properties of Infilled Joint}

3.2.1. Shear Properties within Different Undulating Angles. In this section, the infilled ratio of the joint is 0.5 . Undulating angles are $16.7^{\circ}$ and $26.6^{\circ}$. Initial normal stresses are $0.1 \mathrm{MPa}$, 0.3 $\mathrm{MPa}, 0.5 \mathrm{MPa}, 0.7 \mathrm{MPa}, 0.9 \mathrm{MPa}, 1.1 \mathrm{MPa}$, and $1.3 \mathrm{MPa}$. Direct shear tests are conducted under CNS condition. The obtained shear stress-shear displacement curve, normal displacement-shear displacement curve, and normal stressshear displacement curve are shown in Figure 6.

Figure 6(a) shows shear stress curves of infilled joints within different undulating angles. It can be seen if the normal stress is small (e.g., $0.1 \mathrm{MPa}, 0.3 \mathrm{MPa}, 0.5 \mathrm{MPa}$, $0.7 \mathrm{MPa}$, and $0.9 \mathrm{MPa}$ ), the two inflection points and three parts illustrated in the previous section can be observed in the shear stress-shear displacement curve. At the same initial normal stress, the shear strength within an undulating angle of $16.7^{\circ}$ is obviously smaller than that of $26.6^{\circ}$. However, the corresponding displacement shows a contrary relationship which is the displacement with the undulating angle of $16.7^{\circ}$ is larger than that of $26.6^{\circ}$. Furthermore, if the normal stress is large (e.g., 1.1 MPa and 1.3 MPa), the shear stress curve within an undulating angle of $26.6^{\circ}$ only has two parts which are elastic part and failure part, while there are still three parts for the curve of $16.7^{\circ}$. This result indicates that the 

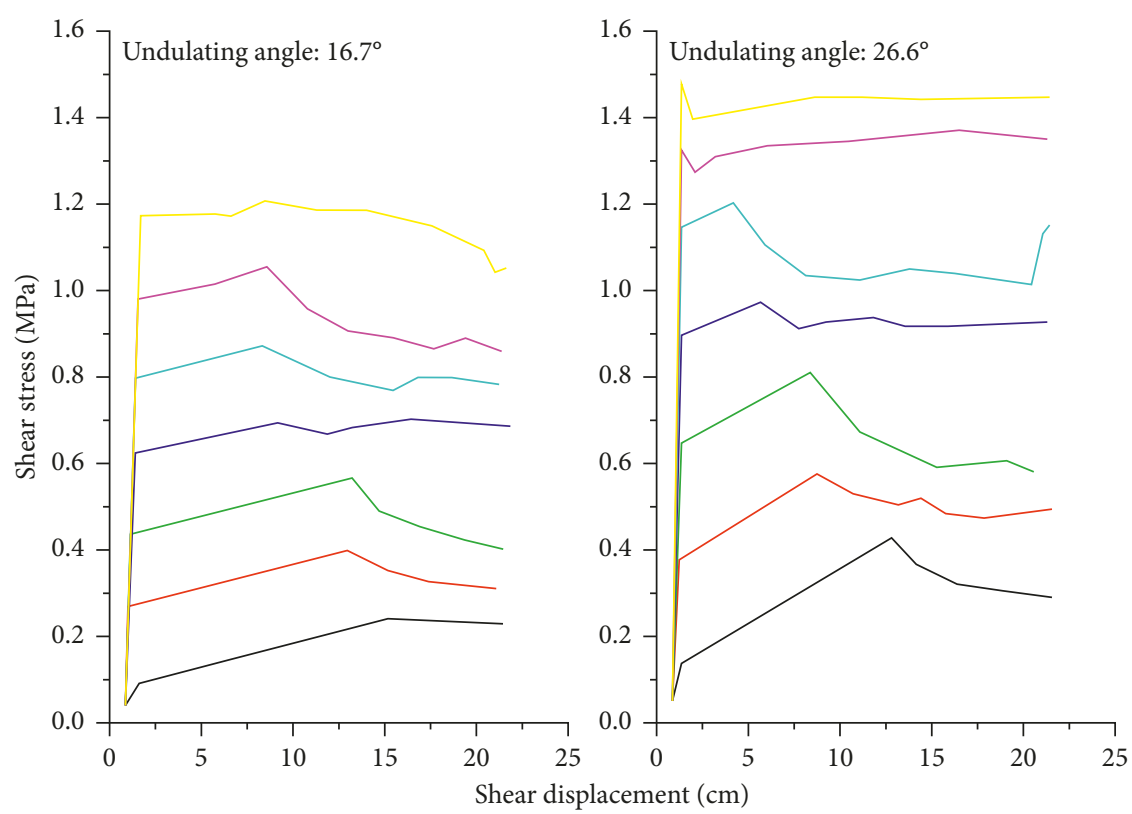

$$
\begin{aligned}
& -0.1 \mathrm{MPa} \\
& -\quad 0.3 \mathrm{MPa} \\
& -\quad 0.5 \mathrm{MPa}
\end{aligned}
$$$$
\text { - } 0.7 \mathrm{MPa}
$$$$
-1.1 \mathrm{MPa}
$$

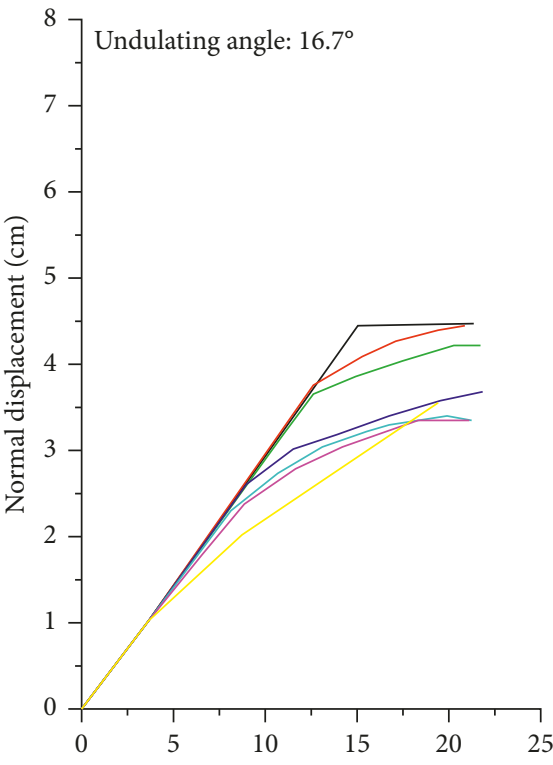

(a)
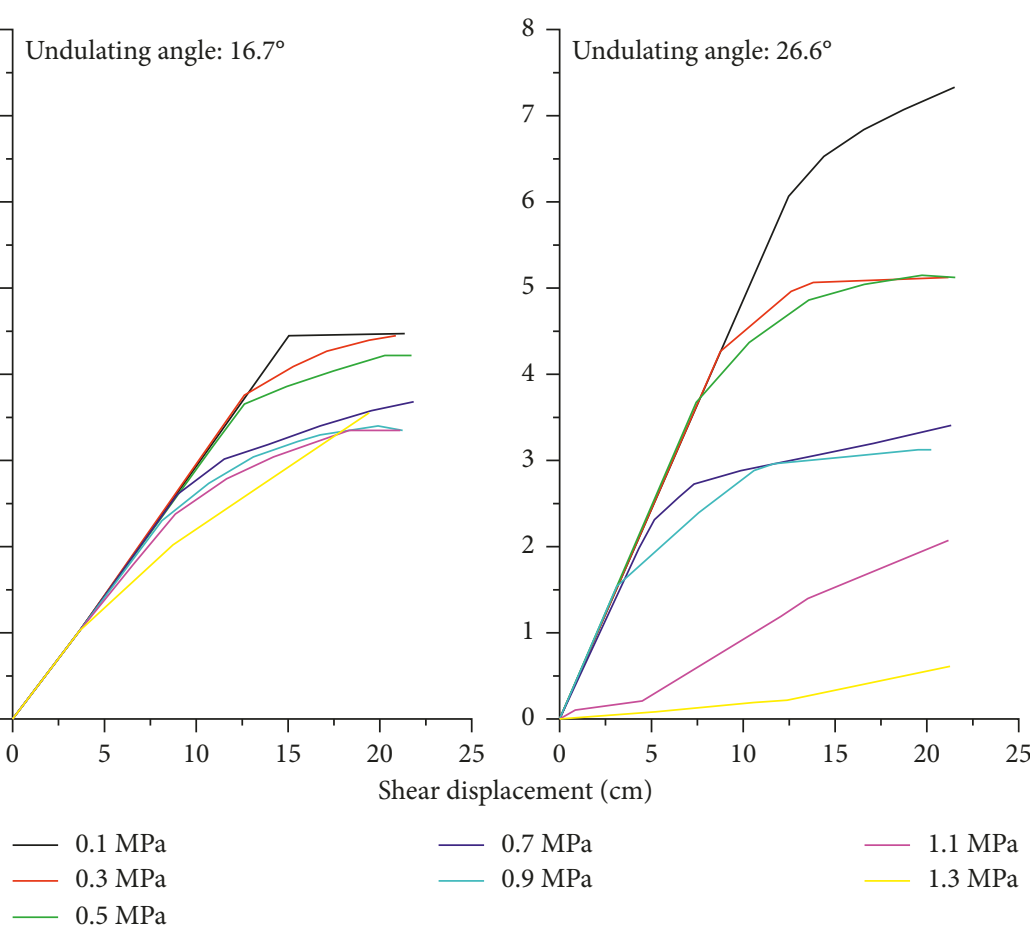

- $1.1 \mathrm{MPa}$

$-0.5 \mathrm{MPa}$

(b)

Figure 6: Continued. 


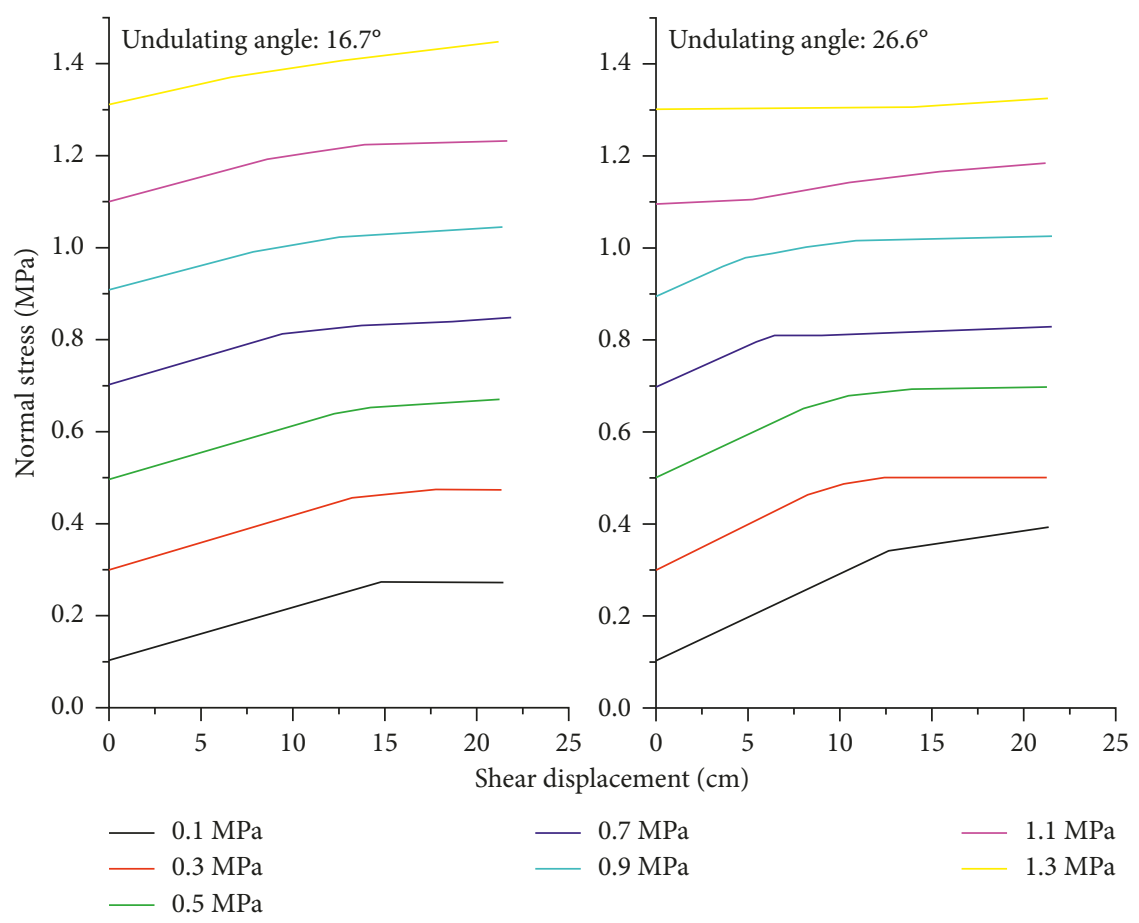

(c)

FiguRE 6: Shearing characteristics curve of the infilled joint with different undulating angles. (a) Shear stress-shear displacement curve. (b) Normal displacement-shear displacement curve. (c) Normal stress-shear displacement curve.

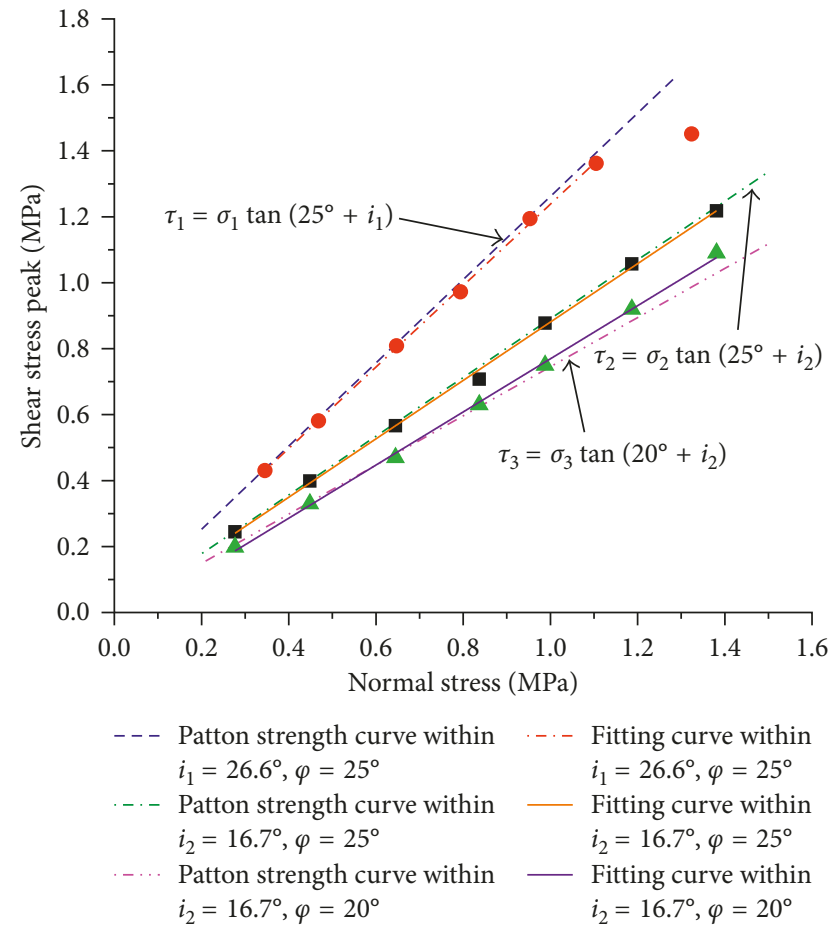

FIGURE 7: Shearing strength curve of the infilled joint with different undulating angles and friction angles.

failure mode will change from sliding failure to shear failure of sawtooth due to the increase in the undulating angle at a relatively high normal stress condition.
The reason causing the above results seem to be that the small undulating angle of sawtooth has a relatively small resistance to the shear motion of the infilled joint, so the joint is more likely to slide along the contour line. In contrast, the large undulating angle contributes to a large resistance to the shear motion resulting the crush of sawtooth is more likely to occur in the shear process with the large undulating angle.

\subsubsection{Shear Strength Curves within Different Undulating} Angles. Figure 7 shows the shear strength curve of infilled joints with different undulating angles.

It can be seen that the shear strength curve of $16.7^{\circ}$ can be fitted in a linear relationship perfectly while the curve of $26.6^{\circ}$ also can be fitted in a linear relationship at a low normal stress level. However, once the normal stress increases to a certain value, the shear strength curve with the large undulating angle presents nonlinear distribution. This is caused by the change of the failure mode that is changing from sliding to cutoff failure. In addition, the slope of the strength curve with $26.6^{\circ}$ in low normal stress level is obviously larger than that with $16.7^{\circ}$ which means that the increase of the undulating angle can effectively raise the friction angle of infilled joints. Furthermore, an additional investigation of influence of the interface (between rock and fillings) friction angle on shear strength of infilled joints was also conducted based on the numerical model. It can be seen in Figure 7 that the shear strength of infilled joints declined along with decreasing of the friction angle (from $25^{\circ}$ to $20^{\circ}$ ) under the undulating angle of $16.7^{\circ}$. And the shear strength 

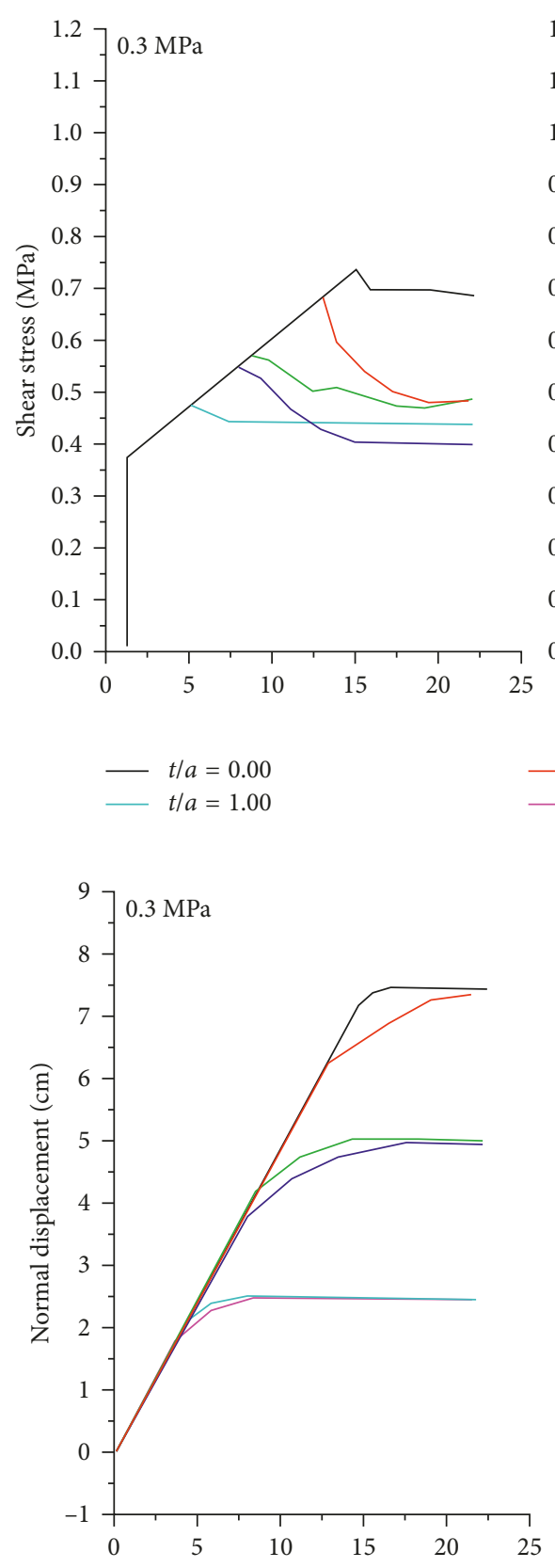
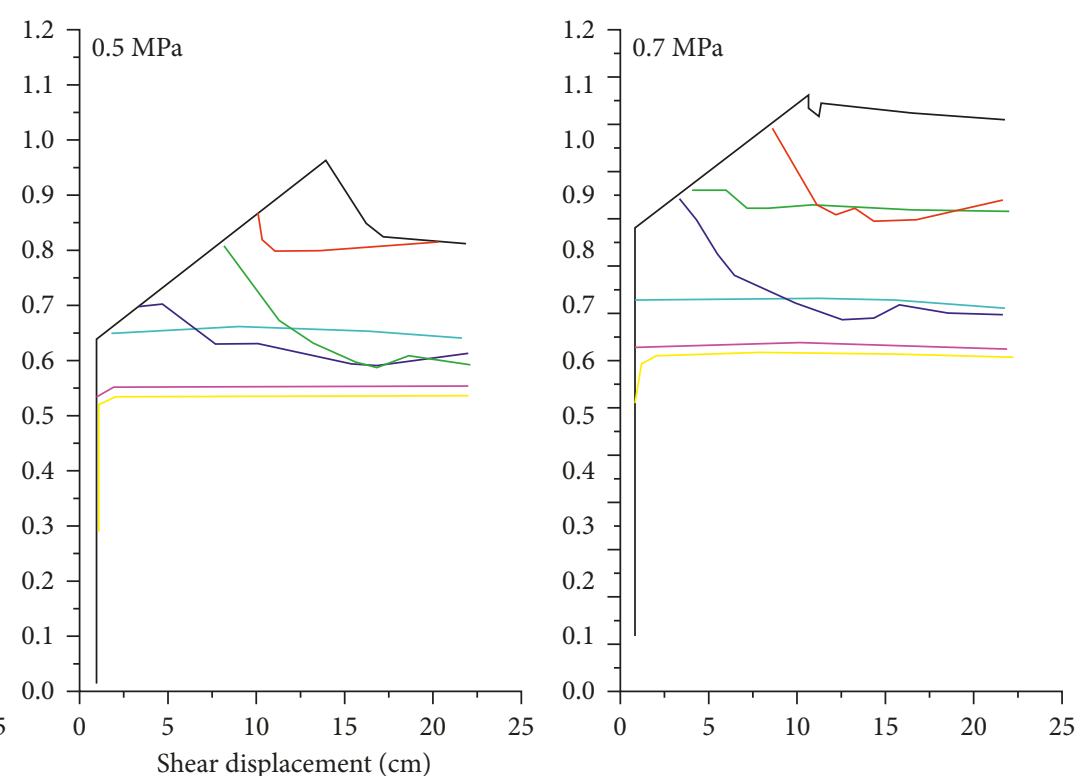

$\begin{aligned}-t / a & =0.50 \\ t / a & =1.50\end{aligned}$

$-t / a=0.75$

(a)
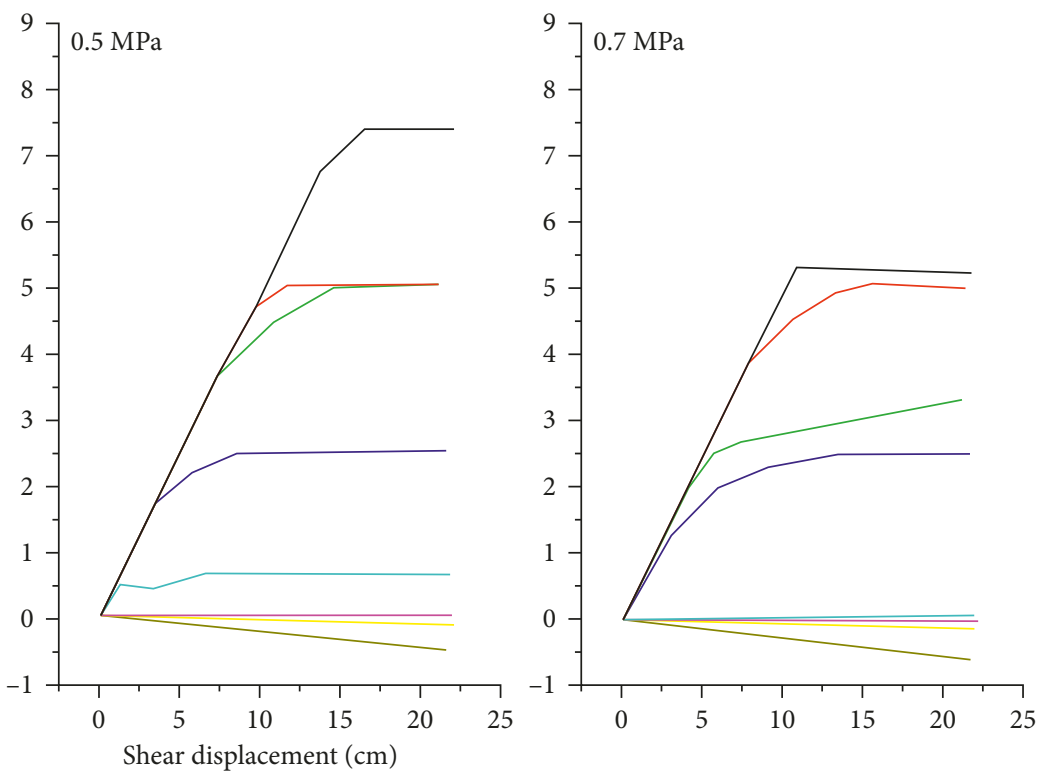

$-\quad t / a=0.25$ $\begin{aligned}-t / a & =0.50 \\ t / a & =1.50\end{aligned}$

$-\quad t / a=0.75$

$-t / a=2.00$

(b)

FIgURE 8: Continued. 


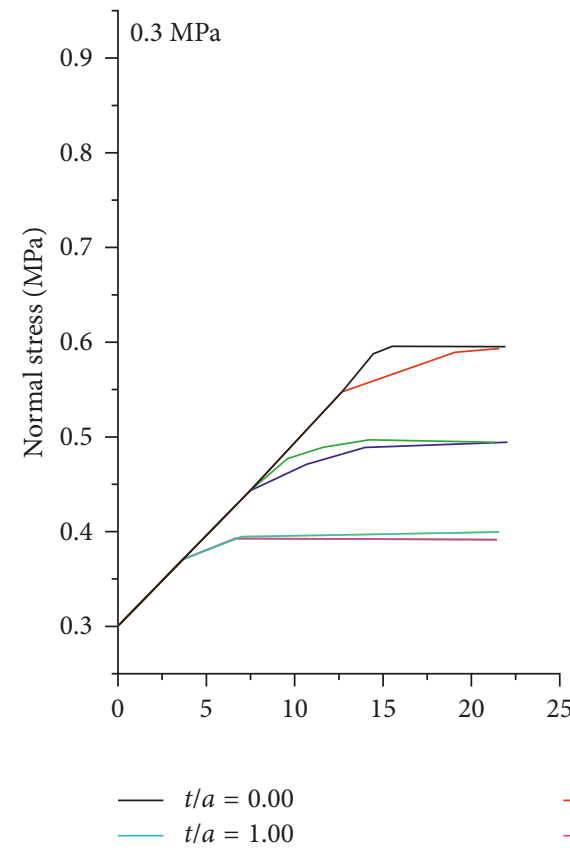

$t / a=1.00$

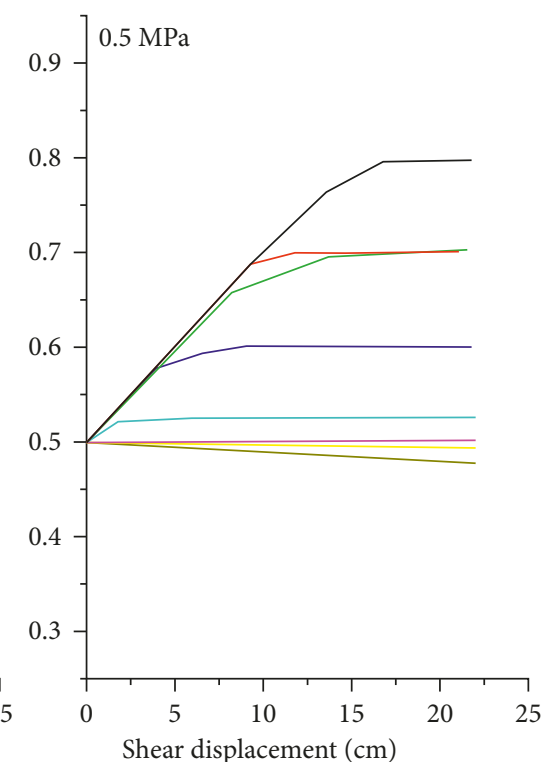

Shear displacement $(\mathrm{cm})$

$t / a=0.25$

$t / a=1.25$

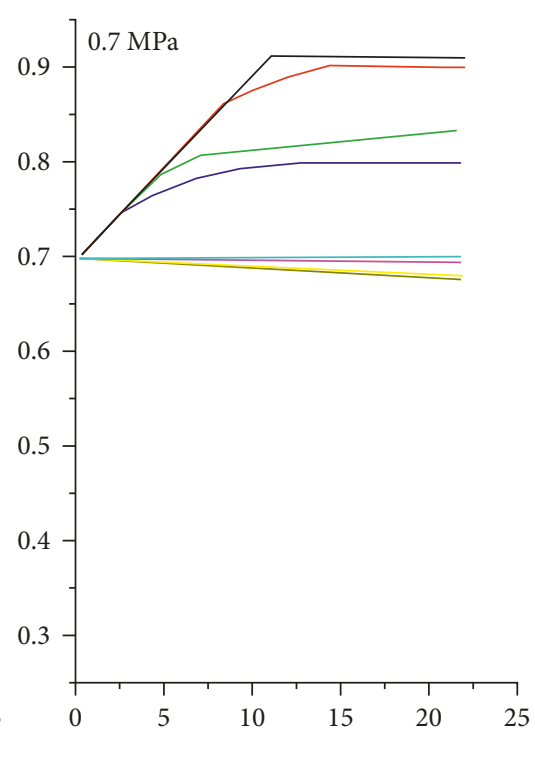

$t / a=0.50$

$t / a=1.50$

(c)

FIGURE 8: Shearing characteristics curve of the infilled joint with different infilled ratios $t / a$. (a) Shear stress-shear displacement curve. (b) Normal displacement-shear displacement curve. (c) Normal stress-shear displacement curve.

of infilled joints under this condition (undulating angle: $16.7^{\circ}$ and interface friction angle: $20^{\circ}$ ) also increased linearly which is the same as that when the friction angle is $25^{\circ}$ and undulating angle is $16.7^{\circ}$.

Patton [27] proposed a mathematical model, as shown in the following equation, to predict the shear strength of the sawtooth joint:

$$
\tau=\sigma \tan (\varphi+i)
$$

where $\tau$ is the shear strength, $\sigma$ is the normal stress, $\varphi$ is the friction angle of interface, and $i$ is the undulating angle.

As shown in (2), the equivalent friction angle of infilled joints can be seen as the sum of the interface friction angle and the undulating angle. Put the corresponding friction angle $\left(25^{\circ}\right.$ and $20^{\circ}$ ) and undulating angle $\left(16.7^{\circ}\right.$ and $\left.26.6^{\circ}\right)$ into (2), respectively, and draw three kinds of curves in the coordinate system. It can be seen from Figure 7 that the fitted curves are in accordance with the Patton shear strength curve, which indicates that the numerical results have a very good agreement with the shear strength model proposed by Patton [27].

\subsection{Influence of Infilled Ratio on Shear Properties of Infilled Joint}

3.3.1. Shear Mechanical Curves within Different Infilled Ratios. In the contrast tests of this section, the undulating angles of the model is $26.6^{\circ}$, and the infilled ratio of joint is $0,0.25,0.5,0.75,1.0,1.25,1.5$, and 2.0 , respectively. Direct shear tests are conducted under CNS condition, and the initial normal stresses are $0.3 \mathrm{MPa}, 0.5 \mathrm{MPa}$, and 0.7 $\mathrm{MPa}$. The obtained shear stress-shear displacement curve, normal displacement-shear displacement curve, and normal stress-shear displacement curve are shown as Figure 8.

Figure 8(a) shows the shear stress-shear displacement curves with the initial normal stress of $0.3 \mathrm{MPa}, 0.5 \mathrm{MPa}$, and $0.7 \mathrm{MPa}$. It can be seen that if the infilled ratio remains stable at a certain value, the shear strength rises in a certain degree with the increase of initial normal stress. On the contrary, if the initial normal stress remains stable at a certain value, the failure mode of infilled joints will change with the increase of the infilled ratio.

It can be seen from Figures $8(a)$ and $8(b)$ that when the normal stress is $0.3 \mathrm{MPa}$, the shear stress-shear displacement for different infilled ratios can be divided into three parts as mentioned previously. The shear displacement in the yield part decreases with the increase of the infilled ratio. The reason of this result is that the proportion of filling in a sawtooth height will rise due to the increase of the infilled ratio. Correspondingly, the failure position will move to the sawtooth root gradually which will reduce the shear displacement in the yield part.

As shown in Figure 8(a), as for the initial normal stress is $0.5 \mathrm{MPa}$, the shear stress curve shows the three stages as discussed above for the infilled ratio less than 1.0. On the contrary, the shear stress curve only has two parts for the infilled ratio larger than 1.0. It can be seen that once the infilled ratio rises to or exceeds 1.0, the corresponding shear strength reduces significantly. If the infilled ratio is less than 1.0, the top block will slide along the contour line of sawtooth at the beginning. Then, once the force between sawteeth reaches the shear strength of sawtooth containing that of fillings, the sawtooth will be cut off. In contrast, when the infilled ratio is larger than 1.0, the thickness of fillings 


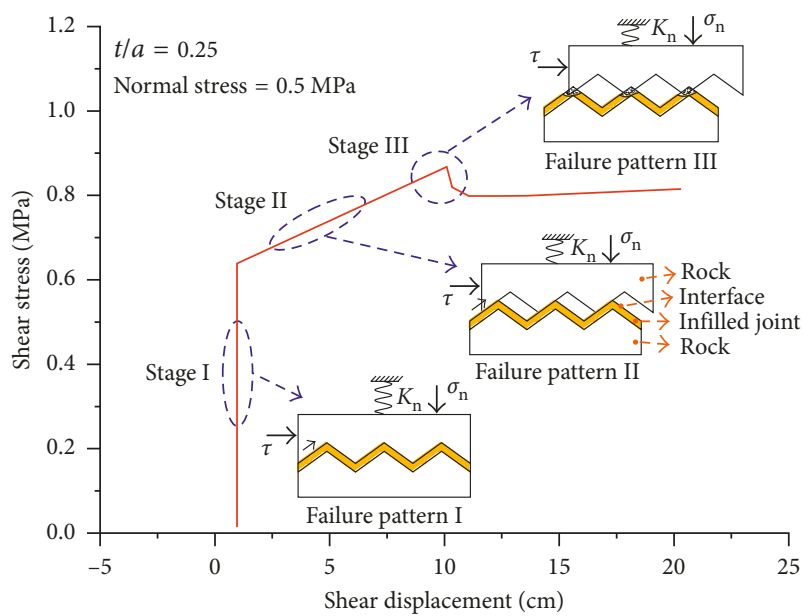

Figure 9: Three different shear failure stages of infilled joints corresponding to different failure modes.

exceeds the height of sawtooth. In this situation, the top block will cut off the sawtooth directly instead of sliding along the contour line of sawtooth. This results in a significant reduction of infilled joints shear strength. Therefore, the yield section cannot be observed in the stressdisplacement curve when the infilled ratio is larger than 1.0. A physical sketch as shown in Figure 9 was also drawn to reflect three different failure modes of infilled joints based on the shear stress-shear displacement curve under the infilled ratio of 0.25 and normal stress of $0.5 \mathrm{MPa}$. It can be seen that failure of the interface between rock and filling happens in the first stage which can be seen as an elastic stage. Furthermore, rock slides along the interface which is the yielding stage. Then, as the final failure stage, the sawtooth will be cut off. This is because that the shear strength of infilled joint is smaller than that of fillings at the beginning of shear motion.

It should be noted that when the infilled ratio equals to 1.0, which means the thickness of fillings is the same as the height of sawtooth, there is no yield section in the stress-displacement curve. However, the shear strength of the infilled joint is larger than that of fillings, as shown in Figure 8(a). This is because the compression of fillings during shear process will induce the antishear ability of rock. Compared with the stressdisplacement curve under $0.5 \mathrm{MPa}$, the curve under $0.7 \mathrm{MPa}$ only shows an increase in shear strength, and the other characteristics have few differences.

As shown in Figure 8(b), with $0.3 \mathrm{MPa}$ of initial normal stress, the top block slides along the contour line of sawtooth for each infilled ratio. For $0.5 \mathrm{MPa}$ and $0.7 \mathrm{MPa}$ of initial normal stress, the relative thick filling has a large compression deformation during shearing process. Under CNS condition, the normal stress applied on the infilled joint decreases due to shear compression, and correspondingly, the shear strength also shows a significant reduction as shown in Figure 8(c).

3.3.2. Influence of Infilled Ratio on the Shear Stress Peak. Figure 10 illustrates the relationship between the infilled ratio and peak of shear stress.

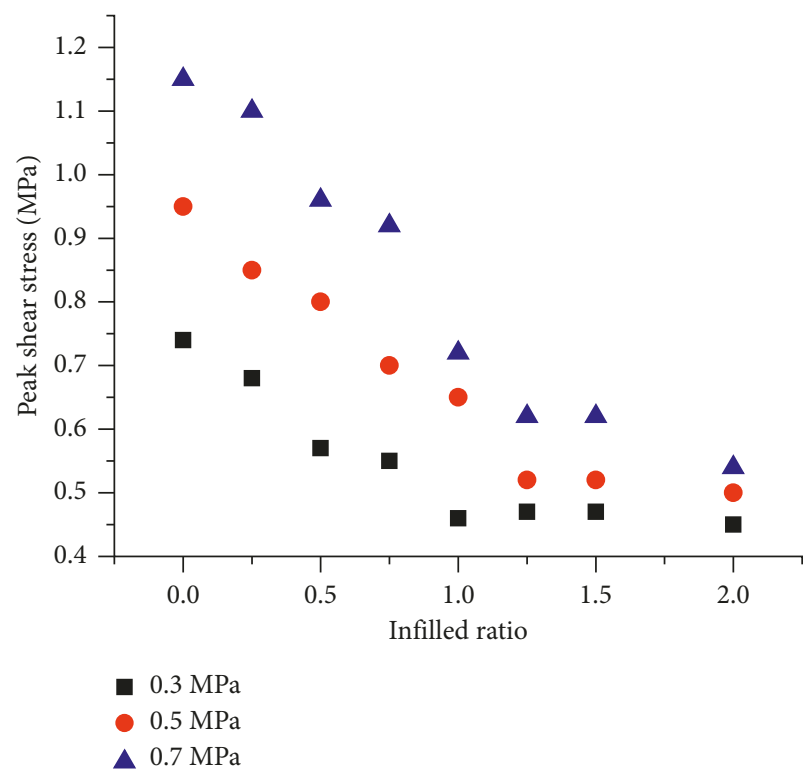

FIgURE 10: Shear stress peak evolution with different infill ratios.

It can be seen from Figure 10 that if the initial normal stress keeps stable, the peak of shear stress of the infilled joint decreases gradually with the increase of the infilled ratio. When the infilled ratio is less than 1.0, the rock height within a sawtooth height decreases gradually with the increase of the infilled ratio which will bring a reduction in shear strength of the infilled joint correspondingly. When the infilled ratio is larger than 1.0, the shear strength of the infilled joint depends on the mechanical properties of filling, so the change of peak of shear stress is not obvious when the infilled ratio is larger than 1.0. Meanwhile, it can be seen that when the infilled ratio reaches 1.0, the shear stress peak decreases to the minimum value for the initial normal stress of $0.3 \mathrm{MPa}$. However, for the higher initial normal stress such as $0.5 \mathrm{MPa}$ and $0.7 \mathrm{MPa}$, the critical value of the infilled ratio with which the shear stress peak reduces to minimum value rises to 1.25 .

In conclusion, numerical results of the paper have a good agreement with the experimental results obtained by Indraratna, Papaliangas et al., and Goodman and the numerical results of Xu and Ren [12,15-17]. Numerical results in this paper show that there is a certain critical value for the infilled ratio. If the infilled ratio is less than the value, the shear strength of the infilled joint is controlled by both rock and fillings and will decrease gradually with the growth of the infilled ratio. When the infilled ratio reaches the critical value, the shear strength of infilled joints is mainly influenced by the mechanical properties of fillings and only has little changes with the increase of the infilled ratio. Meanwhile, the results also indicate that this critical value of the infilled ratio is not necessarily to be 1.0 which will increase along with initial normal stress. This is presumably owing to the exertion of rock shear behaviors due to the compression deformation of fillings. Based on a series of laboratory tests, Indraratna [12] also acquired the similar conclusion that the critical value is between 1.4 and 1.8 , and the value of 1.4 corresponds to the larger initial normal stress. As for the 
larger initial normal stress, the shear dilatancy of the infilled joint will be weakened gradually and even changes to be compression. Furthermore, it will eventually reduce the shear strength of the infilled joint. The numerical result shows a good agreement with the experimental results obtained by Indraratna, Papaliangas et al., and Phien-wej et al., respectively $[12,15,23]$.

\section{Discussion}

By comparing the numerical results with the previous experimental results, it can be found that the numerical model is able to conduct the direct shear test under CNS condition. Numerical results are able to reflect the corresponding shear behaviors of infilled joints under CNS condition. However, the numerical model still has several drawbacks. First of all, the infilled joints modeled in this paper are idealized as sawtooth shape for simplifying the research. Therefore, the simulation of effects of irregular surface on the shear behaviors of natural joints is expected to be studied in future. Secondly, interface was established between the infilling and the upper rock block, while no interface was considered on the lower side of the infilling. This is because firstly, lab measurements indicate that shear failure of rock joints typically occurs at one side of the fillings where the cohesion is smaller [28-31]. Secondly, establishing interface elements on both sides of the fillings usually will lead to many errors during calculating and is computationally expensive. Therefore, it is not necessary to build interface on both sides of the fillings in the model. Finally, the Mohr-Coulomb criterion used in the numerical model is not able to reflect the postpeak mechanical characteristics of rock. Therefore, the future study will focus on the model establishment of natural irregular joint, mechanical parameters determination, and representative constitutive models. Based on these studies, the numerical direct shear test is expected to reflect the shear behaviors of the infilled joint more veritably.

\section{Conclusions}

In this paper, the direct shear test under CNS condition for infilled joints was implemented in the numerical method. Based on the contrast tests, the paper studied the effects of different factors including normal constraints, undulating angle, and infilled ratio on the shear behaviors of infilled joints. A few conclusions are highlighted. Numerical simulation results reveal that the shear failure mode of infilled joints is influenced by initial normal stress, undulating angle, and infilled ratio. If the shear strength of interface between rock and filling is smaller than that of fillings, infilled joints will generate sliding failure along the interface. Otherwise, then the sawtooth will be cut off. The change of the shear failure model, that is, transforming from sliding failure to sawtooth cutoff failure, will induce the nonlinear distribution of the shear strength curve of infilled joints. This indicates that the numerical model shows a good agreement with experimental results available in literatures. Compared with traditional rock shear experiment, numerical simulation is also able to quantify the effect of multiple factors on shear properties of infilled joints such as initial normal stress and infilled ratio more effectively. Therefore, this study proposed and verified an effective numerical analysis method capable of studying the effects of normal stress, undulating angles, and infilled ratio on the shear behavior of infilled rock joints.

\section{Data Availability}

The data used to support the findings of this study are available from the corresponding author upon request.

\section{Conflicts of Interest}

The authors declare that there are no conflicts of interest regarding the publication of this paper.

\section{Acknowledgments}

This research was supported by the National Natural Science Foundation of China (51474209) and State Key Laboratory of Mining Disaster Prevention and Control co-founded by Shandong Province and the Ministry of Science and Technology (MDPC201808).

\section{References}

[1] B. Indraratna, M. Jayanathan, and E. T. Brown, "Shear strength model for overconsolidated clay infilled idealised rock joints," Geotechnique, vol. 58, no. 1, pp. 55-65, 2008.

[2] B. Indraratna, D. A. F. Oliveira, E. T. Brown, and A. P. de Assis, "Effect of soil-infilled joints on the stability of rock wedges formed in a tunnel roof," International Journal of Rock Mechanics and Mining Sciences, vol. 47, no. 5, pp. 739-751, 2010.

[3] B. Indraratna, D. A. F. Oliveira, and E. T. Brown, "A sheardisplacement criterion for soil-infilled rock discontinuities," Geotechnique, vol. 60, no. 8, pp. 623-633, 2010.

[4] H. Senaka Welideniya, Laboratory Evaluation and Modelling of Shear Strength of Infilled Joints under Constant Normal Stiffness (CNS) Conditions, University of Wollongong, Wollongong, NSW, Australia, 2005.

[5] W. G. Xiao, Theoretical Study on Constitutive Model of Jointed Rock Mass and Its Micro-Mechanics Method, Beijing Jiaotong University, Beijing, China, 2011.

[6] L. Shi, M. F. Cai, and J. Zhao, "Failure mechanism and experiment of infilled joints," Journal of University of Science and Technology Beijing, vol. 34, no. 3, pp. 253-259, 2012.

[7] R. Tulinov and L. Molokov, "Role of joint filling material in shear strength of rocks," in Proceedings of the ISRM symposium, pp. II-1-II-24, Nancy, France, 1971.

[8] R. D Lama, "Influence of clay fillings on shear behaviour of joints," in Proceedings of the 3rd Congress International Association of Engineering Geology, vol. 2, pp. 27-34, Madrid, Spain, 1978.

[9] P. E. C. de Toledo and M. H. de Freitas, "Laboratory testing and parameters controlling the shear strength of filled rock joints," Geotechnique, vol. 43, no. 1, pp. 1-19, 1993.

[10] J. P. Pereira, "Rolling friction and shear behaviour of rock discontinuities filled with sand," International Journal of Rock Mechanics and Mining Sciences, vol. 34, no. 3-4, pp. 244. e1-244.e17, 1997. 
[11] B. Ladanyi and G. Archambault, "Shear strength and deformability of filled indented joints," in Proceedings of the 1st International Symposium on the Geotechnics of Structurally Complex Formations, pp. 317-326, Capri, Italy, 1977.

[12] B. Indraratna, "Shear behaviour of idealized infilled joints under constant normal stiffness," Geotechnique, vol. 49, no. 3, pp. 331-355, 1999.

[13] B. Indraratna, W. Premadasa, and E. T. Brown, "Shear behaviour of rock joints with unsaturated infill," Geotechnique, vol. 63, no. 15, pp. 1356-1360, 2013.

[14] B. Indraratna, W. Premadasa, E. T. Brown, A. Gens, and A. Heitor, "Shear strength of rock joints influenced by compacted infill," International Journal of Rock Mechanics and Mining Sciences, vol. 70, pp. 296-307, 2014.

[15] T. Papaliangas, S. R. Hencher, A. C. Lumsden, and S. Manolopoulou, "The effect of frictional fill thickness on the shear strength of rock discontinuities," International Journal of Rock Mechanics and Mining Sciences \& Geomechanics Abstracts, vol. 30, no. 2, pp. 81-91, 1993.

[16] R. E. Goodman, The Deformability of Joints: Determination of the In-Situ Modulus of Deformation of Rocks, Special Technical Publication (ASTM), No. 477, American Society for Testing and Materials, Philadelphia, PA, USA, 1970.

[17] L. Xu and Q. W. Ren, "Numerical simulation of joints shear strength with different infilled ratio," Coal Geology \& Exploration, vol. 3, pp. 52-55, 2007.

[18] M. A. Kanji, "Unconventional laboratory tests for the determination of the shear strength of soil-rock contacts," in Proceedings of the 3rd Congress International Society on Rock Mechanics, pp. 241-247, Denver, CO, USA, 1974.

[19] H. K. Kutter and A. Rautenberg, "The residual shear strength of filled joints in rock," in Proceedings of the 4th International Congress on Rock Mechanics, pp. 221-227, Montreux, Switzerland, 1979.

[20] G. Barla, F. Forlati, and A. Zaninetti, "Shear behaviour of filled discontinuities," in Proceedings of the International Symposium on Fundamentals of Rock Joints, pp. 163-172, Bjorkliden, Sweden, 1985.

[21] P. Bertacchi, A. Zaninetti, G. Barla, and F. Forlati, "Laboratory tests on the shear behaviour of filled discontinuities," in Proceedings of the International Symposium on Engineering in Complex Rock Formation, pp. 262-270, Beijing, China, 1986.

[22] Itasca Consulting Group, Fast Lagrangian Analysis of Continua in 3 Dimensions, User Manual, Version 3.1, Itasca Consulting Group, Minneapolis, MN, USA, 2004.

[23] N. Phien-wej, U. Shrestha, and G. Rantucci, "Effect of infill thickness on shear behaviour of rock joints" in Proceedings of the International Conference on Rock Joints, N. R. Barton and O. Stephansson, Eds., pp. 289-294, Balkema, Loen, Norway, 1990.

[24] J. W. Park and J. J. Song, "Numerical method for the determination of contact areas of a rock joint under normal and shear loads," International Journal of Rock Mechanics and Mining Sciences, vol. 58, no. 7, pp. 8-22, 2013.

[25] M. Bahaaddini, G. Sharrock, and B. K. Hebblewhite, "Numerical direct shear tests to model the shear behaviour of rock joints," Computers and Geotechnics, vol. 51, pp. 101-115, 2013.

[26] S. Thirukumaran and B. Indraratna, "A review of shear strength models for rock joints subjected to constant normal stiffness," Journal of Rock Mechanics and Geotechnical Engineering, vol. 8, no. 3, pp. 405-414, 2016.

[27] F. D. Patton, Multiple modes of shear failure in rock and related materials, Ph.D. thesis, University of Illinois, Urbana, IL, USA, 1966.
[28] N. Barton, "Review of a new shear-strength criterion for rock joints," Engineering Geology, vol. 7, no. 4, pp. 287-332, 1973.

[29] W. F. Li, J. B. Bai, S. Peng, X. Y. Wang, and Y Xu, "Numerical modeling for yield pillar design: a case study," Rock Mechanics and Rock Engineering, vol. 48, no. 1, pp. 305-318, 2014.

[30] W. F. Li, J. B. Bai, J. Y. Cheng, S. Peng, and H. L Liu, "Determination of coal-rock interface strength by laboratory direct shear tests under constant normal load," International Journal of Rock Mechanics and Mining Sciences, vol. 77, pp. 60-67, 2015.

[31] Z. Z. Zhang, J. B. Bai, Y. Chen, and S Yan, "An innovative approach for gob-side entry retaining in highly gassy fullymechanized longwall top-coal caving," International Journal of Rock Mechanics and Mining Sciences, vol. 80, pp. 1-11, 2015. 


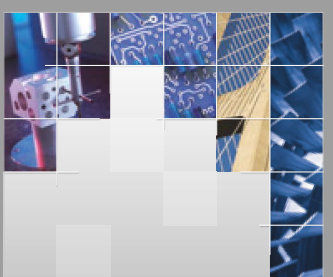

\section{Enfincering}
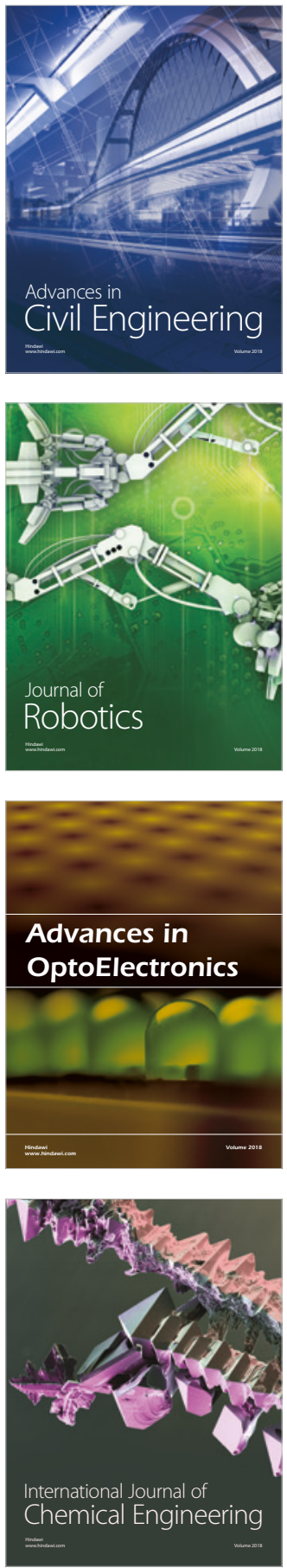

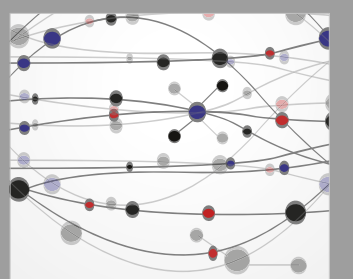

\section{Rotating \\ Machinery}

The Scientific World Journal

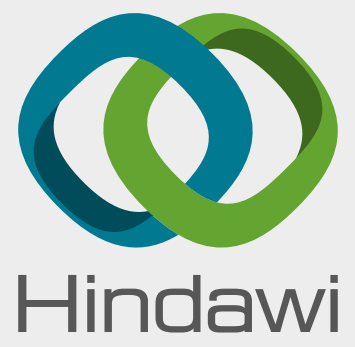

Submit your manuscripts at

www.hindawi.com
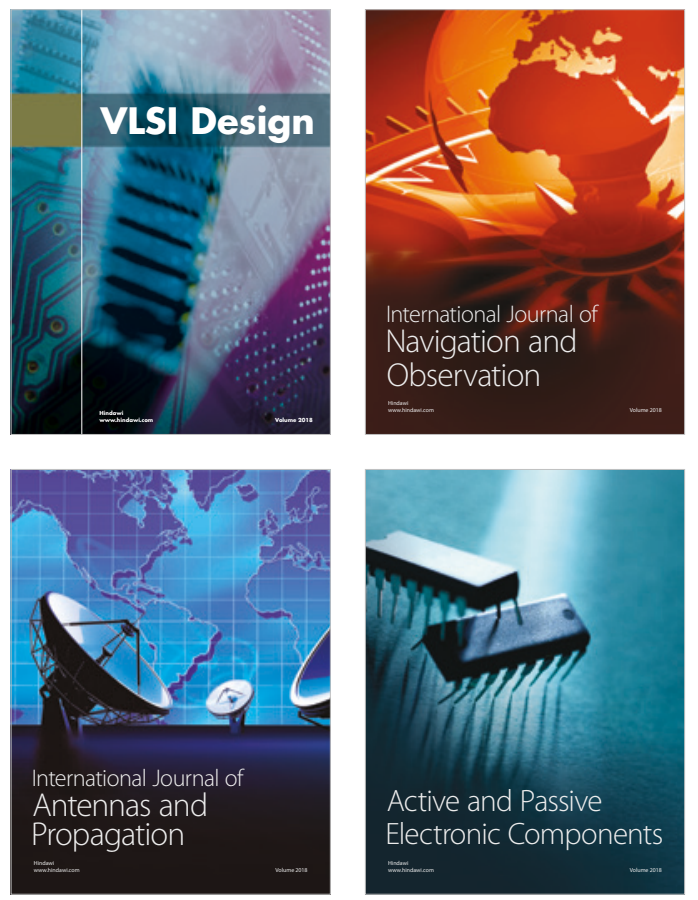
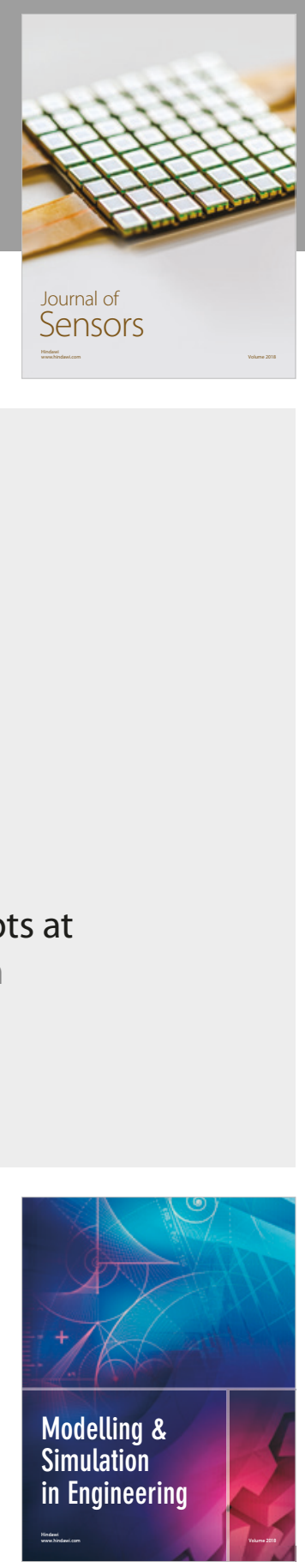

\section{Advances \\ Multimedia}
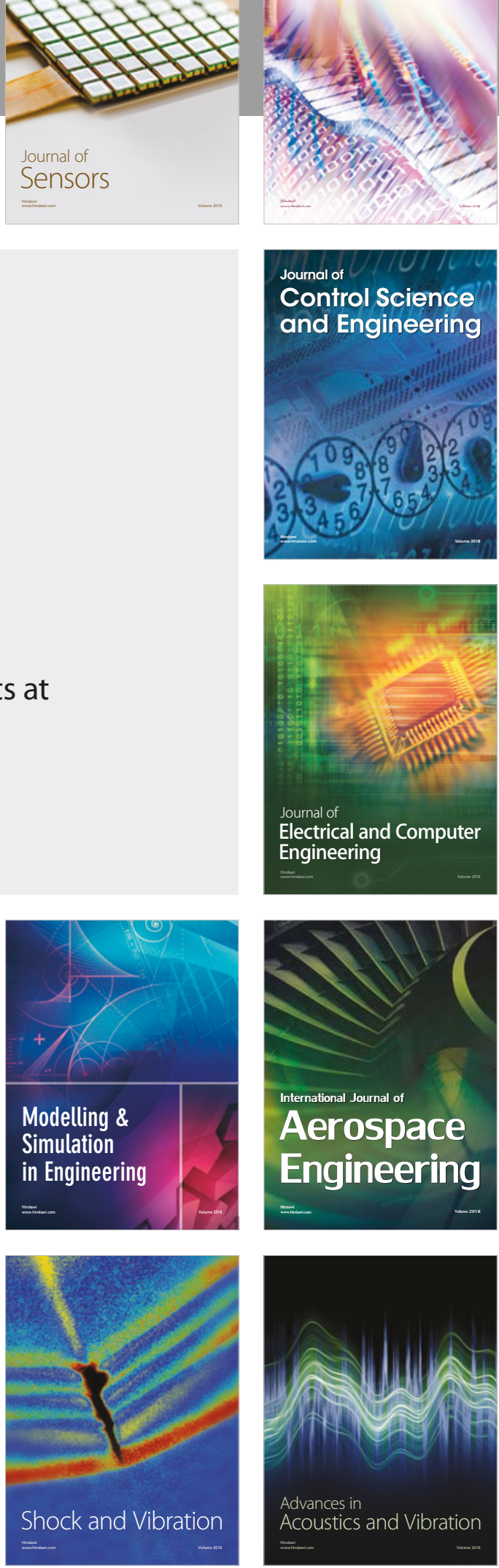